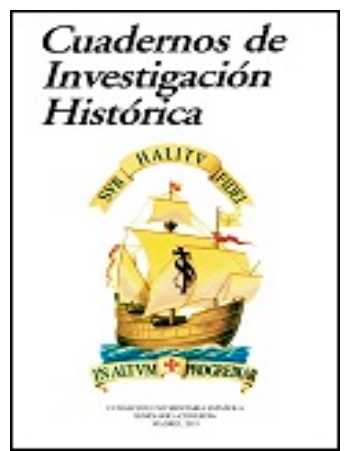

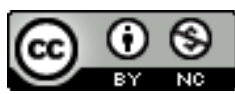

Cuadernos de Investigación Histórica N. ${ }^{\circ} 38$

Año: 2021

Publicación del SEMINARIO DE HISTORIA "CISNEROS"

de la Fundación Universitaria Española

e-ISSN: $2660-5880$

DOI: https://doi.org/10.51743/cih.204

Recibido: 30-05-2021 | Revisado: 15-11-2021 |

Aceptado: 20-11-2021 | Publicado: 26-11-2021

\title{
LOS DERECHOS DE LA MUJER: DE LA REPÚBLICA A LA DICTADURA PASANDO POR LA GUERRA CIVIL
}

\author{
THE RIGHTS OF WOMEN: FROM THE REPUBLIC TO THE \\ DICTATORSHIP GOING TRHOUGH CIVIL WAR
}

\author{
DRA. TIFFANY-MILAGROS SÁNCHEZ-CABEZUDO RINA \\ (Universidad Rey Juan Carlos) \\ Dialnet: producción científica
}

\section{Resumen}

A principios del S.XX era habitual ver que la mujer no podía participar en la vida pública, el sufragio femenino le estaba completamente vedado, quedando su esfera reducida a la vida privada. Como consecuencia se produjo una fuerte división sexual y clasista del trabajo. Su lugar era el hogar cuidando de la familia. Como consecuencia de esta situación tuvieron una escasa formación lo que hacía que dependieran, más aún si cabe, del marido, en el caso de la mujer casada, o del padre, para las mujeres solteras. La República permitió que la capacidad de obrar de la mujer se ampliara, llegando a ocupar altos cargos y reconociéndolas el derecho de sufragio femenino. Permitió que la mujer demostrara que no sólo valía para ser ama de casa sino también para ser una ciudadana de pleno derecho. Con la guerra civil y la conquista de los territorios por parte del bando falangista hizo que sus pensamientos e ideas se fueran implantando en la sociedad. Al final, la Dictadura forjó que la mujer retrocediera todos los pasos que había conseguido dar hasta ese momento, pero el haber experimentado la libertad que había obtenido años atrás hizo que el espíritu revolucionario no desapareciera, sino que quedara apaciguado, para luego volver a resurgir en los últimos años de la etapa dictatorial.

Palabras claves: Dictadura, República, guerra civil, derecho de sufragio, Sección Femenina, Mujer. 


\section{Abstract}

At the beginning of the 20th century women faced significant social inequality and could not participate in public life. Notably, female suffrage was forbidden at this time and their lives were reduced to the private sphere. This period was characterized by a strong division of labour based on class and gender. Women were expected to perform unpaid labour in the home, looking after their families and answering to the men in their lives. Consequently, there were few opportunities to seek professional training, increasing the dependence on husbands, in the case of married women, or their fathers if they were single. The Republic empowered women and provided new opportunities that would offer upward social mobility. For example, they were permitted in politics and could realize the potential to work for higher-up positions. Women began to be recognized as active participants in society, resulting in an increase in equality and a shift from the stigma that historically marked them as homemakers. In the same moment, the civil war was taking hold of Spain along with the Falangist conquest of territories. As a result, previous thoughts and ideas were once again implanted in society and reversed any immediate progress towards social equality. However, the dose of freedom experienced during the Republic left behind a revolutionary spirit, one which re-remerged in the final years of the dictatorial stage.

Key words: Dictatorship, Republic, civil war, right to vote, Women's Section, Woman.

\section{Introducción}

La posición que la mujer ocupa actualmente en nuestra sociedad, no podríamos entenderla sin hacer mención tres momentos claves: la República, la Guerra Civil y la Dictadura.

Durante la II República se reconocieron muchos de los derechos de los que hoy disfruta la mujer, pero que les habían estado vedados. Uno de los más importantes fue el derecho de sufragio activo femenino, aunque una gran parte de los defensores de la República se opuso a ello alegando que; otorgar el derecho de voto a la mujer era poner en peligro la República.

Aun así, las reformas republicanas fueron muy importantes y el papel de la mujer cambió por completo, aunque como señala Ortiz Heras; "la mujer no representó una prioridad, pues seguían ocupando un espacio marginal en lo público, y sólo diez mujeres llegaron a ser diputadas en las Cortes Republicanas"1. Como señala este autor, la labor de la República tendió más a la conquista de los derechos culturales de la mujer.

De esta forma, podemos afirmar que, apoyando la posición del citado autor, el feminismo, entendido como la reivindicación los derechos políticos del sexo femenino, llegó más adelante, concretamente en la última etapa de la Dictadura, puesto que las influencias de otros países más avanzados en lo que a derechos de la mujer refiere fueron muy fuertes, culminando con la entrada de la Democracia.

\footnotetext{
${ }^{1}$ ORTIZ HERAS, M. (2006) Mujer y Dictadura Franquista, Aposta. Revista de ciencias Sociales, núm. 28 , p. 2.
} 
Durante la Guerra civil, los logros que se habían conseguido se vieron tambaleados. El papel más importante en este momento lo tuvo la Sección Femenina de Falange y Auxilio Social. Estas organizaciones, fieles defensoras del Régimen, se encargaron de ayudar a las familias de los presos, dar asistencia a los soldados heridos y enfermos, manteniendo los depósitos y lavaderos y confeccionando ropa o enviándola al frente ${ }^{2}$. Aunque no faltaron mujeres milicianas que se unieron a la guerra para luchar por la República.

Con la caída de la República se produjo un gran retroceso, los derechos de las mujeres fueron suprimidos al igual que lo fue su capacidad de obrar. La Sección Femenina y Auxilio Social se encargaron de adoctrinar a las mujeres y enseñarlas a ser fieles esposas y buenas madres. Lo más importante en esta etapa era; la familia.

En este trabajo de investigación nos hemos propuesto hacer un análisis comparativo de cómo eran los derechos de la mujer en los tres momentos más importantes de la historia de España; la República, la Guerra Civil y la Dictadura. Dentro de la Dictadura hemos distinguido a su vez dos fases; la fase de restricción y la fase de liberación. La fase de restricción coincide con el fin de la Guerra Civil y la entrada del Régimen, en ella los derechos de las mujeres fueron limitados. Por su parte, la fase de liberación comenzó con el último período de la Dictadura, se produjeron unos pequeños cambios sociales y legislativos que, aunque no podemos hablar de un cambio radical, sí de reformas sosegadas.

\section{Primera etapa: la II República}

El inicio del siglo $X X$ viene caracterizado por la posición que la mujer tenía en la sociedad, el de fiel esposa y madre ${ }^{3}$. Su presencia en la esfera pública era escasa, de hecho, aquellas mujeres que querían triunfar en el ámbito literario tenían que hacerlo haciéndose pasar por un hombre, es el caso de Fernán Caballero, pseudónimo utilizado por Cecilia Böhl de Faber y Ruiz de Larrea ${ }^{4}$. Los años previos a la II República están contextualizados en un ambiente muy conservador y con una clara sociedad patriarcal influenciada por un fuerte catolicismo. Es destacable la falta de formación educativa que sufría el sexo femenino, pues como señala Morant "tanto los centros públicos como los privados priorizaron las labores de manos" ${ }^{\text {, de }}$ hecho, las escuelas que estaban divididas por sexos, las asignaturas del hogar no se impartían para el hombre, y aquellas otras como la aritmética, lectura o escritura no tenían el mismo peso para el sexo femenino que para el masculino ${ }^{6}$.

Por consiguiente, la II República llegó marcada por un gran cambio social, la Constitución Republicana proclamó la igualdad de sexos en su artículo 25 que hasta

${ }^{2}$ GIL GASCÓN, F. y GÓMEZ GARCÍA, S. (2014) El uso propagandístico de la mujer nacional durante la guerra civil: 'noticiario español' (1938-1939), Índex Comunicación, núm. 4, p. 159. https://journals.sfu.ca/indexcomunicacion/index.php/indexcomunicacion/article/view/161.

${ }^{3}$ GARCÍA BASAURI, M. (1978) La mujer en el reinado de Alfonso XIII. Una aproximación al primer movimiento feminista español, Tiempo de Historia, núm. 46, pp. 26-39. https://gredos.usal.es/bitstream/handle/10366/29139/THIV N46 P26-

39.pdf? sequence $=3$ \&isAllowed $=y$.

${ }^{4}$ ESTARLICH MARTORRELL, M. (2018) La mujer en los años de la II República: una lectura propia, Revista hispanoamericana de historia de las ideas, núm. 39, p. 95.

${ }^{5}$ MORANT, I. (2006) Historia de las mujeres en España y América latina, Cátedra, Madrid, p. 442. Véase también a PECHARROMÁN, J. L., (2006) Segunda República Española (1931-1936). Biblioteca Nueva, Madrid, p. 97.

${ }^{6}$ ESTARLICH MARTORRELL, M. (2018) La mujer en los años de la II República: una lectura propia, Revista hispanoamericana de historia de las ideas, núm. 39, p. 95. 
ese momento no existía; "no podrán ser fundamento de privilegio jurídico, la naturaleza, la filiación, elsexo, la clase social, la riqueza, las ideas políticas ni las creencias religiosas". El que este artículo quedara redactado de esta manera fue gracias a la diputada Clara Campoamor que reclamó que se suprimieran las palabras "en principio" que recogía el anteproyecto de la Constitución Republicana por "los hombres y las mujeres son plenamente iguales" lo que dio lugar a enmendar el artículo modificando el mismo ${ }^{7}$.

En el artículo 36 de la misma Norma Fundamental se reconoció el derecho de sufragio femenino, aunque el mismo no se aprobó libre de polémicas ${ }^{8}$. Cabe recordar que durante la Dictadura de Primo de Rivera se reconoció el derecho de voto, pero para algunas mujeres, como las solteras o viudas, según el decreto de 12 de abril de 1924, para los comicios municipales ${ }^{9}$.

El derecho de sufragio activo femenino fue criticado por una gran parte de los parlamentarios republicanos, incluso por las diputadas Victoria Kent o Margarita Nelken. Ésta última señalaba que "no es cuestión de capacidad; es cuestión de oportunidad para la República. Poresto pido el aplazamiento del voto femenino o su condicionalidad; pero si condicionamos el voto de la mujer, quizá pudiéramos cometer alguna injusticia. Si aplazamos el voto femenino, no cometemos injusticia alguna, a mi juicio. Entiendo que la mujer, para encariñarse a un ideal, necesita algún tiempo de convivencia con el mismo ideal. La mujer no se lanza a las cuestiones que no ve claras y por esto entiendo que son necesarios algunos años de convivencia con la República; que vean las mujeres que la República ha traído a España lo que no trajo la Monarquía"10. En otras palabras, consideraba que era necesario aplazar el voto de la mujer para que primero se mentalizara y viera lo que se consigue con la República ya que la mujer no era tan arriesgada como el hombre, y después decidiera ${ }^{11}$.

Por ello mismo, gran parte de los republicanos votaron en contra de conceder este derecho a la mujer por miedo a que, la mujer votara a favor de la derecha ${ }^{12}$. El conflicto se manifestó en el debate de la sesión constituyente del 1 de octubre de 1931 cuando la intervención del diputado Carrasco y Formigueras provocó un aluvión de abucheos por parte del resto de diputados. En su intervención señaló que "el votar a favor del derecho de sufragio femenino era admitir el principio de igualdad de sexos y por tanto votar a favor de la República y de la Democracia". Así, reclamaba a los demás miembros republicanos que "no se podía admitir la posibilidad de que sólo tuvieran voto la mitad de los ciudadanos españoles".

Como réplica al temor de que las mujeres al ser católicas pudieran votar a favor de la derecha, señalaba el citado diputado que "la mitad de los ciudadanos españoles son republicanos en su mayor parte, y hay entre estos republicanos muchos católicos y muchas católicas. En mucha parte los católicos y las católicas son

\footnotetext{
${ }^{7}$ ESTARLICH MARTORRELL, M. La mujer en los años de la II República: una lectura propia, Óp. cit., p. 102.

${ }^{8}$ RAMOS PALOMO, M. (2001) Feminismo y acción colectiva en la España de la primera mitad del siglo XX, en Manuel Ortiz Heras, David Ruiz González e Isidro Sánchez Sánchez (Coordinadores), Movimientos sociales y estado en la España contemporánea, Cuenca, UCLM, p. 379-403.

${ }^{9}$ GÓMEZ BLESA, M. (2010) Modernas y vanguardistas: mujer y democracia en la II República, Ediciones del Laberinto, Madrid, p. 222.

${ }^{10}$ Diario de sesiones constituyentes del 1 de octubre de 1931.

${ }^{11}$ MARTÍNEZ SIERRA, M. (1931) La mujer española ante la República, Ediciones de la Esfinge, Madrid, p. 55.

${ }^{12}$ VENTURA FRANCH, A. (1999) Las Mujeres y la Constitución Española de 1978, Ministerio de Trabajo y Asuntos Sociales, Instituto de la Mujer, Madrid, pág. 83. Hemos señalado que se reconoce el derecho de sufragio activo femenino, pues cabe recordar que el pasivo ya estaba reconocido.
} 
republicanos como lo soy yo (...)". Consideraba así que, existía un ambiente de intolerancia que él como demócrata no podía permitir ${ }^{13}$.

Por su parte, el diputado republicano Franco señaló que, las aspiraciones eran otorgar el voto a la mujer, no a partir de los 23 años sino a partir de los 21 años. Sin embargo, aun así, consideraba que la mujer tenía que tener el voto por dos razones; la primera, porque era de justicia en la República ya que ésta se había conseguido gracias a los hombres y a las mujeres, y la segunda razón era que el sentimiento pacifista del mundo sólo llegaría a ser realidad cuando las mujeres tuvieran el voto ${ }^{14}$.

Como posiciones en contra a reconocer este derecho tenemos al diputado republicano Álvarez Buylla, que explicaba que el motivo, no era otro que; "porque otorgar el derecho a voto a la mujer era otorgarla un arma en contra de la República"15. Por su parte Novoa Santos, catedrático de la Universidad de Madrid, creía que la mujer no estaba preparada para votar, e Hilario Ayuso llegaba a señalar que la mujer era deficiente en voluntad y en inteligencia, hasta que cumplía los 45 años. Compartimos la postura de Estarlinch cuando señala que; "los republicanos mantienen actitudes misóginas, pensando que las mujeres son histéricas por naturaleza, y que una mujer sólo puede votar racionalmente después de la menopausia, ya que el ciclo menstrual las perturba" ${ }^{16}$.

Por su parte, intelectuales de la época como Miguel de Unamuno, Gregorio Marañón y Ortega y Gasset, se posicionaron a favor del voto a la mujer puesto que consideraban, como así manifestaron en sus artículos, que el clero no podía influenciar a la mujer ni hacer campaña política desde el confesionario. En cierto modo, estaban reconociendo que la mujer tenía suficiente capacidad cómo para decidir su voto, sin que el sacerdote pudiera utilizar el sacramento de la confesión para influir en su pensamiento político ${ }^{17}$.

El debate en las cámaras llegó a tal extremo que, Azaña marcó que, "sólo hay dos mujeres en la sala -refiriéndose a Margarita Nelken y a Clara Campoamor- y están enfrentadas, ¿qué ocurrirá cuando sean cincuenta las que actúen? ${ }^{18}$

Al final, salió adelante aprobándose el 1 de octubre de 1931, gracias al recelo de los republicanos, que fue aprovechado por los partidos conservadores, y especialmente a la tenacidad de la diputada Clara Campoamor ${ }^{19}$. Podemos considerar que este momento supone el hito fundamental para conseguir el pleno reconocimiento de las mujeres como ciudadanas.

Las peticiones de Clara Campoamor eran muy ambiciosas, no sólo reclamaba el derecho de voto sino también conseguir que se reconociera el divorcio y la igualdad de los hijos habidos dentro y fuera del matrimonio. Por ello, la Constitución Republicana reconoció en el artículo 43 el derecho de igualdad de ambos sexos dentro del matrimonio, concediéndose la posibilidad de disolución con la Ley de 2

\footnotetext{
${ }^{13}$ Diario de sesiones constituyentes del 1 de octubre de 1931.

${ }^{14}$ Ibídem.

${ }^{15}$ Ibídem.

${ }^{16}$ ESTARLICH MARTORRELL, M. La mujer en los años de la II República: una lectura propia, Óp. cit., 110

${ }^{17}$ Ibidem.

${ }^{18}$ Ibídem.

${ }^{19}$ CAMPOAMOR, C. (2001) Mi pecado mortal. El voto femenino y yo, Instituto Andaluz de la Mujer, Sevilla 2001, p. 155
} 
de marzo de 1932. Con esta Ley se permite poner a España al mismo nivel que gran parte de los países europeos que ya lo habían reconocido.

Con la entrada en vigor de la Ley del Divorcio, se recogió que entre los años 1932 y 1936 del total de demandas presentadas, el $56 \%$ fueron interpuestas por mujeres, el resto por los hombres ${ }^{20}$. Esto nos hace concluir que la mujer se estaba viendo liberada de la situación patriarcal que había estado sufriendo, de hecho, los hijos serían iguales con independencia de si habían nacido o no dentro del matrimonio. Esta situación para la Iglesia Católica supuso un fuerte revés, ya que además hay que añadir que en el año 1932 se reconoció el matrimonio civil, siendo esto el detonante para que la Iglesia se posicionara a favor de los partidos conservadores ${ }^{21}$.

En lo que al ámbito laboral refiere, la mujer había venido sufriendo una discriminación salarial ya que por el mismo trabajo cobraban, según Núñez Pérez ${ }^{22}$, entre un $47 \%-75 \%$ más el sexo masculino que el femenino. La poca formación de la mujer hacía que tuvieran puestos de baja cualificación. Téngase en cuenta que su formación iba dirigida a saber atender las necesidades de esposa y madre. El que la mujer no entrara en el mundo laboral tenía como finalidad que los cimientos de la familia no se viesen tambaleados ${ }^{23}$. Margarita Nelken realizó un análisis de la situación laboral que la mujer tenía en ese momento, y concluyó que: "La posición de sometimiento a la cual se ha visto reducida secularmente la mujer no es nada relacionado con una realidad natural, sino que se trata de un mito, como lo es, también, el factor del determinismo biológico y funcional con el que se pretende justificar el inevitable dominio del varón sobre la base de diferencias biosociológicas entre los sexos en lo relativo al temperamento, a la habilidad cognitiva y al rol desempeñado en la sociedad"24. En otras palabras, la mujer ha quedado siempre sometida al marido, dando por hecho que el hombre es un ser con unas características "superiores" que nada tienen que ver con la realidad. Sin embargo, con la aprobación de la Norma Fundamental Republicana se reconoció que la mujer podía ejercer una profesión, valorando su capacidad y mérito para acceder al mismo. Aun así, hubo bastantes detractores tanto de progresistas como de conservadores que consideraban que la mujer no estaba preparada todavía para realizar ciertos trabajos.

En el ámbito penal, se derogó el adulterio y el amancebamiento. Además, se aprobaron leyes para proteger a las mujeres prostitutas, a través del Decreto de 1 de junio de 1931 que suprimió el Real Patronato para la Represión de la Trata de Blancas. Más tarde se aprobó el Decreto de 1931 por el que se fundaba el Patronato de Protección a la Mujer, aunque duró muy poco, porque en 1935 se disolvió y sus funciones quedaron relegadas al Consejo Superior de Protección a la Infancia, y en ese mismo año se anuló el reglamento que reconocía la prostitución como vehículo para ganarse la vida de forma lícita.

La situación que la mujer sufría era resumida por Margarita Nelken como "la mujer es igual al hombre ante la ley únicamente para sufrir las condenas. No se reconoce su discernimiento como ser humano, pero se reconoce su plena responsabilidad

${ }^{20}$ MORAGA GARCÍA, M. (2008) Notas sobre la situación jurídica de la mujer en el franquismo, Feminismos, p. 230

${ }^{21}$ NICOLÁS MARÍN, E. (2005) La libertad encadenada. España en la dictadura franquista 19391975, Madrid, Alianza, p. 149.

${ }^{22}$ NUÑEZ PEREZ, G., (1993) Evolución de la situación laboral de las mujeres en España durante la Segunda República (1931-1936). Cuadernos Relaciones laborales, núm. 3, p. 31.

${ }^{23}$ NASH, M. (2003) Dones ciutadanes a Catalunya: la Segona República, Historia de les dones, Setmanari el temps, Valencia, núm. 4, p. 53-58

${ }^{24}$ NELKEN, M. (2013) La condición social de la mujer en España. Madrid, horas y horas, en ESTARLICH MARTORRELL, M. La mujer en los años de la II República: una lectura propia, Óp. cit., p. 98. 
ante la culpa". Es decir, la mujer no era igual que el hombre en materia de beneficios, sin embargo, si cometía un hecho delictivo éste era igual o más grave que el del hombre, aunque fueran exactamente idénticos ${ }^{25}$.

En lo referente a la educación, en 1931 se autorizó la creación del Instituto-Escuela en Barcelona que permitía la coeducación ${ }^{26}$.

Como podemos observar, esta etapa se caracteriza principalmente por querer acabar con un estado patriarcal, donde la mujer tuviera la misma posición que el hombre dentro de la familia, por ello, en este momento la autoridad no sólo la ostentaba el padre sino también la madre. Pero realmente los avances no fueron del todo gracias a los partidos republicanos, sino principalmente a Clara Campoamor y Victoria Kent. Quepa por adelantado que, en cuestiones femeninas como señala Díez Fuentes, los partidos de izquierdas mostraban poco interés ${ }^{27}$, aunque sí reclamaron de la mujer una conducta más revolucionaria. De hecho, una limitación que nos encontramos en la Constitución Republicana es la imposibilidad de que la mujer pudiera acceder a la presidencia del gobierno, pues sólo serían elegibles aquellos ciudadanos españoles que sean mayores de 40 años y que gocen de sus derechos civiles y políticos. Es decir, no señalaba que pudiera ser sin distinción de sexos, lo cual es claro que los mismos partidos republicanos temían la presencia de la mujer en los puestos de poder.

Aunque fue un proceso lento y gradual en el que la mujer empieza a hacerse oír, como señala Estarlich ${ }^{28}$, la población activa femenina fue aumentando, haciendo que las mujeres jóvenes y solteras ocuparan puestos tanto en el sector secundario como terciario de la sociedad conllevando que tuvieran que emigrar a las ciudades. El pensamiento de las mujeres empezó a cambiar y desde los partidos de izquierdas se reclamó que lucharan por conseguir la igualdad. Por ello mismo, la revolución de las mujeres fue dirigida a acabar con los pensamientos tradicionales que se habían impuesto sobre la mujer y el hombre, liberar a la mujer de esa esclavitud del hogar, y luchar por reconocer el amor libre, y los métodos anticonceptivos. Hemos dicho anteriormente que esta situación fue un golpe bajo para la Iglesia, pues todo el ideario que defendía y que se había impuesto en los años atrás, quedaban totalmente desvirtuados ${ }^{29}$.

Mientras estas reformas se iban fraguando, los conservadores se opusieron a ellas, incluso iban en contra de las ideas revolucionarias que se estaban instaurando en la sociedad. Por ello se promovió Acción Católica Española, Juventud Católica Femenina y la Juventud Agrícola Católica Femenina. La finalidad de estas asociaciones era acallar los movimientos revolucionarios. Para los defensores de la derecha, la mujer estaba siendo deformada ya que se la estaban otorgando roles masculinos. Los movimientos de las mujeres durante los años donde la República era la forma de gobierno, fueron bastante grandes, y las mujeres estaban muy presentes reivindicando la igualdad de sexos, participando en las huelgas. Algo que casi hasta ese momento era impensable en la etapa anterior, pues no sólo por la poca formación que tenían sino también porque no tenían presencia en los sindicatos. En palabras de Estarlich "hasta 1930 su afiliación estaba centrada en los sindicatos católicos, pero con el aumento las luchas y las actitudes se fue

\footnotetext{
${ }^{25}$ Ibídem.

${ }^{26}$ RUIZ FRANCO, R. (2016) La mujer de la República, Espacio, Tiempo y Forma, Historia Contemporánea, tomo 18, p. 165.

${ }^{27}$ DÍEZ FUENTES, M. (1995) República y primer Franquismo; la mujer española entre el esplendor y la miseria, 1930-1950, Ediciones de la Universidad de Alicante, p. 27.

${ }^{28}$ ESTARLICH MARTORRELL, M. La mujer en los años de la II República: una lectura propia, Óp.cit., p. 98.

${ }^{29}$ Ibidem.
} 
radicalizando, estos sindicatos dejaron de crecer, y se producía un fortalecimiento del sindicalismo de clase". Sin embargo, tras otorgar el voto a la mujer, su presencia en los partidos políticos incrementó. $Y$ de esta forma pudieron luchar de forma más directa por conseguir los derechos que alcanzaron ${ }^{30}$.

En el contexto de esta situación, se produce el estallido de la guerra civil española en 1936, siendo el germen de un cambio radical dentro de la sociedad.

\section{Segunda etapa: la Guerra Civil}

El 17 de julio de 1936 estalla la Guerra Civil española, momento en el que la situación de España y de la mujer comenzó a cambiar, la libertad de la que el sexo femenino había venido disfrutando y los avances que se habían conseguido quedaron revocados. La mujer pasa a tener un papel de "mujer sufriente": por un lado, se encontraban las mujeres republicanas que se fueron a luchar en la guerra, por no perder los derechos y libertades que habían logrado, muchas de ellas tuvieron penas de muerte o fueron encarceladas, y por otro lado, las mujeres de derechas que se dedicaron en cuerpo y alma, en la retaguardia, a asistir a los soldados heridos o enfermos y a suministrarles comida y ropa.

Hemos considerado así distinguir dos tipos de mujeres: la mujer de corte republicano y la mujer de corte fascista.

La mujer de corte republicano se movilizó, hicieron un llamamiento a la sociedad para que no se permitiera la situación que se avecinaba y se reunieron en contra del fascismo. Sabían de antemano que la instauración de una Dictadura sólo las traería de vuelta al hogar, sometiéndolas, como así fue, a un estado patriarcal. Se crearon varias organizaciones, las más destacadas fueron Agrupación de Mujeres Antifascistas y Juventudes Socialistas Unificadas.

Agrupación de Mujeres Antifascistas se creó en 1933 aunque sus actuaciones más importantes llegaron con la Guerra Civil. La presidenta de esta agrupación era Dolores Ibárruri (La Pasionaria). Sus objetivos eran luchar contra el fascismo, defender la paz, la cultura y la libertad de la mujer ${ }^{31}$.

Juventudes Socialistas Unificadas nació en marzo de 1936, en el mismo año del estallido de la Guerra Civil, como resultado de la fusión de Unión de Juventudes Comunistas de España del PCE y de las Juventudes Socialistas de España del PSOE. Las bases principales de esta organización fueron: la defensa diaria de los intereses de la juventud trabajadora, educación en el marxismo-leninismo y el internacionalismo proletario, capacitación de los jóvenes obreros para fortalecer y desarrollar la organización y luchar en la vanguardia de la juventud, agrupándola contra el fascismo y por la victoria del socialismo. Durante la Guerra Civil, se organizaron militarmente en el bando republicano ${ }^{32}$. Otra de las organizaciones que también tuvo un gran protagonismo la plataforma de mujeres antifascistas de Cataluña, llamada Unió de Dones de Catalunya, creada en $1937^{33}$.

\footnotetext{
${ }^{30}$ ESTARLICH MARTORRELL, M. La mujer en los años de la II República: una lectura propia, Óp.cit., p. 106.

${ }^{31}$ CARABIAS, J. (1997) Crónicas de la República. Del optimismo de 1931 a las vísperas de la tragedia de 1936. Madrid, Temas de hoy.

32 Véase en http://guerracivil.afinet.org/catalogos/vinyetas/Capitulo\%20VII.pdf.

${ }^{33}$ NASH, M. (1999) Las mujeres republicanas en la Guerra Civil, Taurus, Madrid, p. 76.
} 
Durante la primera etapa de la Guerra Civil muchas mujeres tomaron las armas participando en el combate armado -fue el segundo ejército que tenía al frente mujeres, el primero fue el ejército ruso en 1917-. Se trataban de mujeres vestidas con monos azules, fusiles colgados al hombro cuya finalidad era defender los derechos políticos y sociales que habían adquirido durante la II República. Sin embargo, para Nash la imagen de la mujer miliciana era más bien un símbolo de llamamiento a los hombres para luchar ${ }^{34}$. No obstante, esta situación cambió muy pronto, Largo Caballero - presidente del Consejo de Ministros durante la II República- dio la orden de que las mujeres se retirasen del frente, culpándolas de poner en peligro a los soldados no sólo porque habían sido el motivo de la transmisión de enfermedades venéreas sino también porque eran objeto de distracción sexual para los soldados los cuales, gastaban sus energías en las relaciones sexuales y cuando llegaban al frente no tenían fuerzas para luchar ${ }^{35}$.

Por su parte, las mujeres de corte fascista tuvieron un papel más servicial. Una de las principales protagonistas, al igual que lo fue en el bando republicano La Pasionaria, fue Pilar Primo de Rivera jefa de la Sección Femenina fundada en 1933. La Sección Femenina es el partido femenino de la falange, y su creación se debe a la familia de José Antonio Primo de Rivera. El ideario político era el nacionalsindicalismo y su ideario de vida para las personas era el luchar para contraer matrimonio, casarse, y fundar una familia, con un cabeza de familia como era el hombre, y una mujer sumisa dependiente de él.

Pero durante la guerra civil tuvieron un papel muy importante. Pilar Primo de Rivera recomendó en 1937 que las mujeres se unieran a la Sección para que ayudaran a resolver la situación tan angustiosa que sufrían las familias de huérfanos, y dar asistencia a los soldados. Se organizaron distintas actividades dirigidas a la enseñanza de la enfermería y de actividades asistenciales. Manifestaba la jefa de la Sección Femenina que "allí dondequiera que ella esté vivirá el espíritu de la Falange, y que no habrán estado desatendidos los camaradas y los soldados, porque ella, con la alegría de nuestro estilo, habrá sabido llevarles todo lo que necesitasen sus cuerpos heridos" 36 .

En 1936 nace Auxilio de Invierno, una organización presidida por Mercedes Sanz Bachiller, que al ver la situación social tan desbastadora que estaba viviendo España, decidió crear esta organización con la finalidad de ayudar a los niños huérfanos y a las mujeres viudas. Para ello se crearon comedores infantiles, al frente del mismo estaban mujeres de maridos que habían perdido la vida en la batalla o habían sido encarcelados. El primer comedor social se abrió en 1936 en Valladolid y en diciembre de ese mismo año, se fundaron las Cocinas de Hermandad dedicadas a la atención de parados y ancianos. En 1937 Auxilio Social tenía así; 711 comedores y 158 cocinas. Se abrieron también centros para mujeres embarazadas y lugares de hogar para niños huérfanos o abandonados ${ }^{37}$.

En definitiva, durante la guerra civil española se inicia un proceso de reformas que se fue culminando según las tropas de Franco iban conquistando los territorios

\footnotetext{
${ }^{34}$ Ibidem, pág. 67.

35 ANDRES GRANEZ, H. (2009) Transgrediendo las fronteras del género. milicianas en la guerra civil española, Temas de mujeres, núm. 5, p. 11.

${ }^{36}$ Discurso de Pilar Primo de Rivera en el II Consejo Nacional de la Sección Femenina de F.E.T. y de las J.O.N.S. en Segovia, 1938.

${ }^{37}$ ROCA I GIRONA, J. (1996) De la pureza a la maternidad. La construcción del género femenino en la postguerra española, Ministerio de Educación y Cultura, Madrid.
} 
españoles. Al final, todos los avances que se habían conseguido en la República quedaron demolidos.

\section{Tercera etapa: la Dictadura}

Esta tercera etapa coincide con el fin de la guerra civil e inicio de la Dictadura. La hemos dividido en dos períodos; el de restricción que comienza en el año 1938, y el de liberación, que se inicia en el año 1953.

\section{Período de restricción: 1938 a 1952}

Tras la victoria de Francisco Franco, se inicia un proceso de cambio. Muchas de las mujeres que habían luchado en la guerra fueron obligadas al exilio o asesinadas, y otra gran parte de ellas se vieron obligadas a adoptar el ideario de la Falange, llegando incluso a afiliarse a la Sección Femenina.

El modelo de mujer que prima en esta etapa es el de mujer conservadora, recluida al ámbito doméstico ${ }^{38}$, puesto que como señala Moraga García "el Régimen va a encomendar a las mujeres las sagradas funciones de fortalecer la familia, educar a los hijos en la fe cristiana y en la doctrina falangista, potenciar la tasa de natalidad y ser el refugio y descanso del esposo" 39 .

Una de las primeras modificaciones que se llevó a cabo fue en el año 1938, a punto de finalizar la guerra, con el Fuero del Trabajo. En él se prohibía el trabajo nocturno para la mujer, y algunos puestos quedaban vedados para el sexo femenino, pues a la mujer casada se la liberaba del taller y de la fábrica. Esto es un fiel reflejo de que lo principal en la etapa del Franquismo era la familia, pues, la mujer que se casaba pasaba a ocupar el puesto de madre y esposa, mientras que la mujer soltera al no tener las obligaciones familiares que entraña el matrimonio, disfrutaba así de una mayor libertad. En definitiva, el espacio de la mujer, especialmente el de la mujer casada se reducía a la familia.

En la citada norma ya se empezó a reflejar el cambio que la sociedad española iba a experimentar, cuando se recogió que "el derecho de trabajar es consecuencia del deber impuesto al hombre por Dios, para el cumplimiento de sus fines individuales (...)". Se empezó a pasar de una sociedad laica donde todo vestigio relacionado con Dios había sido eliminado, a una sociedad donde la religión católica era la principal protagonista.

Durante este período la mujer, debía ir bien vestida con ropa que no se vieran detalles del cuerpo, sin que los vestidos marcaran la figura femenina, las faldas o los vestidos debían ir por debajo de las rodillas y las mangas tenían que ser largas, en definitiva, la forma de vestir tenía que evitar la mirada de los hombres. En las playas y en las piscinas se prohibían las prendas indecorosas, los bañadores debían de cubrir el pecho y la espalda, y no ceñirse al cuerpo de la mujer. Fuera del baño no estaba permitido mostrarse ante todo el mundo en bañador o vestirse y desvestirse en público sino en las casetas que estaban construidas para ello. En 1951 se llevó a cabo el Primer Congreso Nacional de Moralidad en playas y piscinas,

\footnotetext{
${ }^{38}$ ORTIZ HERAS, M. (2006) Mujer y dictadura franquista, Óp. cit., p. 3.

${ }^{39}$ MORAGA GARCÍA, M.A. Notas sobre la situación jurídica de la mujer en el franquismo, Óp.cit., p. 231.
} 
celebrado en Valencia, donde se expresó la preocupación que existía por los comportamientos indecentes de las mujeres en las playas. La finalidad de base no era otra que, evitar seducir al hombre casado y provocar con ello la ruptura del matrimonio.

En materia penal, se aprobó la Ley de 11 de mayo de 1942, que reconoció de nuevo el adulterio, castigando con pena mayor a la mujer casada que yace con varón que no fuera su marido, mientras que para el hombre sólo será delito si tuviera manceba dentro de la casa conyugal o notoriamente fuera de ella. Tres años más tarde se incluyó en el Código Penal el delito de uxoricidio por causa de honor, en ella se producía una atenuación si el hombre mataba a la mujer cuando había sido sorprendida en fragante adulterio. Lo mismo para el padre que sorprendiera a la hija en su domicilio si ésta tenía menos de 23 años ${ }^{40}$.

Los delitos de infanticidio se atenuaban cuando la muerte del hijo recién nacido se llevaba a cabo por la madre o los abuelos maternos por ser ilegítimamente concebido, ya que el honor de la familia era lo más importante. Otro fiel reflejo más de la importancia que tenía en la dictadura la unidad familiar.

En lo que refiere a los delitos sexuales, se podía atenuar la pena cuando la mujer otorgaba el perdón al autor del delito o incluso podía extinguirse si ella contraía matrimonio con él.

El aborto estaba penado, recordemos que la Iglesia era una de las protagonistas de la época, por ello se castigaba tanto a la mujer que abortaba como a aquellos que indicaran, vendiera, anunciara, suministraran o divulgaran cualquier medio o procedimiento para facilitar el aborto o inclusive evitar la procreación. Ahora bien, se permitía reducir la pena siempre que una mujer soltera se quedara embarazada y alegara la deshonra para la familia ${ }^{41}$.

En 1941 se creó el Patronato de Protección a la mujer, institución encargada de encerrar a las jóvenes que habían caído o estaban en riesgo de caer en el vicio, en la prostitución. La finalidad del Patronato era reeducarlas sobre la base de unos valores religiosos siendo el eje principal; la familia ${ }^{42}$.

En el ámbito social, la Sección Femenina organizó grupos de mujeres llamadas Hermandad de la Ciudad y el Campo, que antes de finalizar la guerra se encargaron de ocupar puestos que el hombre había dejado desiertos tras marchar al frente, pero que, tras la finalización de la misma, se encargó de enseñar a la mujer campesina en todas las industrias rurales, e incidir en la educación religiosa, política y familiar. El papel de esta Hermandad fue muy importante debido a la ayuda que prestaron a las personas tras la situación tan desoladora que azotaba a España en los años de la postguerra. Se hizo especial hincapié en la enseñanza el cuidado de los bebés para reducir la mortalidad infantil. El discurso de Pilar Primo de Rivera en septiembre de 1939 recogía muy claramente cuál era el fin de la Hermandad: "En este semanario iréis viendo la labor que la Sección Femenina de la Falange Española Tradicionalista y de las J. O. N. S., por medio de la Hermandad de la Ciudad y el Campo, piensa realizar en las aldeas de España. Yo no os digo nada, porque la Sección Femenina tiene la norma de que sus obras sean mejores que sus palabras.

${ }^{40}$ CERVERA, J. (1998) La radio: un arma más de la Guerra Civil en Madrid, Historia y Comunicación Social, núm. 13, p. 263-294.

${ }^{41}$ Ibidem, pág. 4.

${ }^{42}$ OLIVER OLMO, P. y CUBERO IZQUIERDO, M. C., (2020) De los controles disciplinarios a los controles securitarios, Ediciones Universidad de Castilla la Mancha, p. 500. 
Vosotras las veréis, y dentro de unos años, cuando vuestras casas sean más limpias, vuestros hijos más sanos y vuestros campos más fértiles; cuando vuestras hijas no estén ociosas alrededor de la lumbre, sino que, afanosas, las veáis tejiendo y bordando, para que el mundo entero conozca todo el arte popular de nuestra tierra; cuando vuestros hijos no sientan el ansia de la ciudad, porque en su huerto y en su casa encuentren todo lo que necesitan, nos diréis entonces: "La Falange nos trajo la verdad" ; y esa es la única recompensa que esperamos de vosotras, porque lo que no queremos es ser para vosotras como fueron todos. Saludo a Franco. ¡Arriba España!"43.

En tema educativo, la guerra y la postguerra trajo una gran precariedad, y por ello, la Sección Femenina para luchar contra el analfabetismo creó una agrupación de mujeres que se encargó de ir pueblo por pueblo enseñando diferentes materias. Es cierto, que también era una forma de ir calando en la sociedad el espíritu de la Falange. En 1938 se suprimieron las escuelas mixtas, aunque no sería hasta 1945 cuando se consolidó de forma definitiva la segregación de niños y niñas con la Ley de Educación Primaria de 17 de julio. El motivo de la separación de las enseñanzas, según rezaba en el preámbulo era "por razones de índole moral y de eficacia pedagógica", ya que la formación que recibían las mujeres no podía ser la misma que la de los hombres, puesto que las asignaturas como el hogar o economía doméstica estaban dirigidas a ellas, había otras asignaturas comunes como educación física y formación del espíritu nacional, pero que se impartían de forma diferente según fuera dirigido al alumnado masculino o femenino.

Durante la República vimos que una de las cosas por las que luchaba Clara Campoamor, y que consiguió que se aprobara, fue el divorcio. Sin embargo, con la Ley de 23 de septiembre de 1939 quedó derogado con efectos retroactivos, devolviendo "a nuestras Leyes el sentido tradicional, que es el católico"44. Una muestra más de lo más importante en esta etapa, la familia, siendo la mujer la base y el sustento de la misma, algo que con el divorcio no se podía conseguir. En palabras de Pilar Primo de Rivera había que "volver a poner al hombre los pies sobre la tierra. Y para la mujer la tierra es la familia. Por eso, además de darles a las afiliadas la mística que las eleva, tenemos que apegarlas con nuestras enseñanzas a la labor diaria, alhijo, a la cocina, al ajuar, a la huerta, tenemos que conseguir que encuentreallí la mujer toda su vida y el hombre todo su descanso" 45 .

En otras palabras, el hombre era el cabeza de familia, ya la autoridad no la ostentaba el padre y la madre como así se había establecido en la II República, sino que la autoridad dentro del ámbito familiar era del marido, siendo el único interlocutor válido entre la familia y la sociedad ${ }^{46}$. En definitiva, la mujer desde que nacía quedaba sometida primero al padre y luego al marido, y aquellas que decidían meterse a monjas, a Dios. La capacidad de obrar de la mujer quedó tan reducida que se obligó a la mujer casada bajo régimen de sociedad de gananciales, solicitar autorización del marido para diversos actos, lo que se llamó la licencia marital. Rezaba en el artículo 57 del Código Civil que "el marido

\footnotetext{
${ }^{43}$ Discurso de Pilar Primo de Rivera, Madrid, 1 de septiembre de 1939.

${ }^{44}$ Exposición de motivos de la Ley de 23 de septiembre de 1939.

${ }^{45}$ PRIMO DE RIVERA, P. Discursos, circulare, escritos sección femenina de f. E. T. y de las j. O. N. $\mathrm{S}$.

1942, Gráficas Afrodisio Aguado, p. 28

${ }^{46}$ MORAGA GARCÍA, M. A. Notas sobre la situación jurídica de la mujer en el franquismo, Óp.cit., pág. 235.
} 
debe proteger a la mujer y esta obedecer al marido", obligando a la mujer inclusive a obtener la nacionalidad del marido cuando contraía matrimonio ${ }^{47}$.

Sin embargo, si comparamos el trato que recibía la mujer soltera con la casada, éste era mucho mejor pues, una vez alcanzada la mayoría de edad, la mujer gozaba de una cierta libertad que la casada no tenía. La mujer soltera podía trabajar, pero una vez que contraían matrimonio debía dejarlo, y si querían volver necesitaban la autorización del marido. El motivo no era otro que el hecho de que una mujer cuando se casaba debía dedicarse en cuerpo y alma a la familia.

En definitiva, este período llamado de restricción estuvo caracterizado por los cambios legislativos que coartaron la libertad de las mujeres. Pero a partir de 1958 se hizo notar un cambio sustancial.

\section{Período de liberación: 1958 a 1975}

Este período viene caracterizado por un cambio legislativo ${ }^{48}$, que, aunque no dieron lugar a una libertad absoluta y a una plena capacidad de obrar de la mujer, sí que se adoptaron normas que relajaron la situación en el que la mujer había estado sumida. De hecho, Pajot señalaba que "no cabe duda de que la evolución de los derechos de la mujer, orientada a través de una progresiva emancipación, pretendiendo llegar hasta una total igualdad con el marido, constituye una de las características de los tiempos actuales" 49 .

Aunque la sociedad empezó a tomar conciencia de la necesidad de un cambio, había sectores doctrinales lo rechazaban, véase como Castán Tobeñas, señalaba que "no debemos aferrarnos, con actitud retrógrada, a las formas de vida que ya pasaron. Mas tampoco debemos los juristas anticiparnos a la transformación social (...) todo se perdería si al reconocer a la mujer sus valores humanos y sus derechos naturales, protegiendo su libertad y su dignidad, pusiésemos en peligro su feminidad y olvidásemos el interés primordial de la conservación de la familia" 50 .

La primera de las reformas llevadas a cabo en este período se produjo con la ley de 24 de abril de 1958. En ella se reconoció el matrimonio civil como supletorio al canónico, pero siempre que la acatolicidad se diera en ambos contrayentes ${ }^{51}$. Aunque esto dio lugar a una modificación de las rúbricas de las Secciones primera y segunda del capítulo dedicado a las disposiciones generales del matrimonio, que pasó de "formas de matrimonio" a "clases de matrimonio", y según la Exposición de Motivos, el motivo es evitar el riesgo que aquella terminología pudiera ofrecer: la equiparación del matrimonio civil con el canónico, que, por la naturaleza sacramental de éste sería inexacta. Como vemos, no se pierde nunca la piedra angular, la religión católica.

\footnotetext{
${ }^{47}$ Decreto de 2 de mayo de 1938.

${ }^{48}$ ZAMBRANO, M. (1998) Delirio y Destino (los veinte años de una española). Barcelona, Mondadori España, p. 260-261.

49 PAJOT, G. (1954) La mujer casada en el derecho comparado, Revista de derecho notarial, Madrid, p. 140.

${ }^{50}$ CASTÁN TOBEÑAS, J. (1955) La condición social y jurídica de la mujer. La diferenciación de los sexos en sus aspectos biológico, sociológico, ético y jurídico, Reus, Madrid, p. 197.

${ }^{51}$ Ley de 24 de abril de 1958 por la que se modifican determinados artículos del Código civil.
} 
Se modificó también la capacidad jurídica de la mujer, ya que "el sexo por sí solo no puede determinar en el campo del Derecho civil una diferencia de trato que se traduzca, en algún modo, en la limitación de la capacidad de la mujer a los efectos de su intervención en las relaciones jurídicas (...) Si bien es cierto que el sexo por sí no debe dar lugar a diferencias y menos a desigualdades de trato jurídico civil, ha parecido igualmente claro hasta el punto de estimarlo también como principio fundamental que la familia, por ser la más íntima y esencial de las comunidades, no puede originar desigualdades, pero sí ciertas diferencias orgánicas derivadas de los cometidos que en ella incumben a sus componentes, para el mejor logro de los fines morales y sociales que conforme al Derecho natural, está llamada a cumplir. Se contempla, por tanto, la posición peculiar de la mujer casada en la sociedad conyugal, en la que, por exigencias de la unidad matrimonial, existe una potestad de dirección, que la naturaleza, la Religión y la Historia atribuyen al marido, dentro de un régimen en el que se recoge fielmente el sentido de la tradición católica que ha inspirado siempre y debe inspirar en lo sucesivo las relaciones entre los cónyuges" ${ }^{52}$. Pestaña Ruiz señala que ${ }^{53}$, este párrafo es una auténtica declaración de intenciones, y que la desigualdad no viene de la condición biológica de la mujer, sino de otras causas; el matrimonio. Y en cierto modo es así, pues, ya dijimos anteriormente que en la etapa dictatorial lo importante era la familia, y para mantener la familia y hacer que la mujer se dedicase en exclusiva a ella, suponía quedar limitada su capacidad una vez que contraía matrimonio. Y esta esencia, se siguió manteniendo con esta modificación legislativa. De hecho, el apartado séptimo del artículo 237 sustituye la prohibición a toda mujer para ser tutora o protutora por la prohibición solamente a la mujer casada si no ha obtenido la licencia del marido.

Aun así, se pretendió liberar a la mujer de ciertas limitaciones en su capacidad, por ello, se consintió que la mujer fuera parte del consejo de familia, y se eliminó la prohibición de que la mujer fuera testigo en los testamentos. En lo referido al matrimonio, se permitió tanto al hombre como a la mujer, alegar como causa de separación el adulterio de alguno de ellos, y a la madre que contraía matrimonio en segundas nupcias, mantener la patria potestad. $Y$ un cambio muy signifícate y representativo de esta etap ${ }^{54}$, es el otorgar a la mujer la posibilidad de prestar su consentimiento cuando el marido, en sociedad de gananciales, realizaba algún acto dispositivo sobre bienes muebles o inmuebles. Como dice Pestaña Ruiz, "estas facultades se traducen en limitaciones al poder omnímodo masculino, pues pierde el monopolio en la gestión de los bienes gananciales, evitando las nefastas consecuencias que ello comportaba para la mujer" 55 . Se sustituyó también el que la vivienda ya no era "casa del marido" sino "hogar conyugal", es decir, se le dio así un protagonismo en el hogar a la mujer que le había estado vetado.

Tres años más tardes, se aprobó el Decreto 2310/1970 de 20 de agosto, que proclamó que "la mujer tiene derecho a prestar servicios laborales en plena situación de igualdad jurídica con el hombre y a percibir por ello idéntica remuneración". Se trató así de equiparar los derechos laborales de la mujer con los del hombre, sin embargo, la autorización del marido para que la mujer pudiera firmar un contrato de trabajo no fue abolida, aunque se presumía que lo tenía otorgado cuando la mujer ya trabajaba antes de contraer matrimonio, y en caso de separación podía trabajar. Se abolió también la petición de excedencia forzosa para la mujer cuando contraía

\footnotetext{
52 Exposición de motivos de la Ley de 24 de abril de 1958.

${ }^{53}$ PESTAÑA RUIZ, C. (2015) Evolución jurídica de la mujer casada en el sistema matrimonial español de la época preconstitucional, Revista de Estudios Jurídicos, Jaén, núm. 15, p. 27.

${ }^{54}$ MORAGA GARCÍA, M. A. Notas sobre la situación jurídica de la mujer en el franquismo, Óp.cit., p. 237.

55 PESTAÑA RUIZ, C. Evolución jurídica de la mujer casada en el sistema matrimonial español de la época preconstitucional, Óp. cit., p. 28.
} 
matrimonio, y el "depósito de mujeres", esto es, en caso de petición de separación del matrimonio, la mujer ya no tenía que ser depositada en el domicilio paterno.

La mujer ya estaba consiguiendo un mayor protagonismo en la sociedad, dejó de ser considerada un ser destinado a satisfacer las necesidades de la familia, para poder tener su capacidad de decisión. En 1970 se eliminó la posibilidad de que el hombre diera en adopción a los hijos sin consentimiento de la madre ${ }^{56}$.

Aunque la licencia marital no se derogó hasta 1975, en 1972 se permitió a las mayores de edad, pero menores de 25 años, abandonar la casa paterna sin consentimiento del padre, y sin tener que contraer matrimonio o ingresar en un convento ${ }^{57}$. Con esta misma Ley se estableció la mayoría de edad en 21 años para ambos sexos.

A pesar de todas estas reformas las cuales fueron fundamentales, no sería hasta 1975 -meses antes de la muerte de Franco- coincidiendo con el año en el que la ONU declaraba Año Internacional de la Mujer, cuando se llevó a cabo una de las mayores reformas del Código Civil. El que ambos hechos coincidan no es baladí, pues la apertura de España a Europa y el que la mujer se introdujera en el mercado laboral, hicieron que sus conocimientos del exterior y sus relaciones sociales empezaran a crecer.

La mujer dejó de estar recluida en el domicilio y empezó a dialogar de temas que iban más allá de los puramente domésticos. El legislador tuvo que llevar a cabo una reforma sustancial y así lo reconoció en la Exposición de Motivos; "las profundas transformaciones que ha experimentado la sociedad hacen aconsejable y conveniente una revisión del derecho de familia. Tal propósito, sin embargo, sólo debe acometerse de manera prudente, tras un atento y detenido estudio de las posibles soluciones, un análisis de la realidad y de las necesidades verdaderamente sentidas, con la guía también de los elementos que puede aportar el derecho comparado y sin desconocer en ningún caso las exigencias éticas que de modo muy particular inciden sobre este sector del derecho ${ }^{58}$.

Una de las consecuencias del cambio social que se produjo se manifestó en el matrimonio, el cual ya se componía en muchos de ellos por español y extranjero. Por ello mismo, se admite que la mujer no tenga que cambiar de nacionalidad por contraer matrimonio con un extranjero.

Al fin, lo más ansiado del sector femenino llegó, se derogó la licencia marital y se reconoció que la mujer no perdiese su capacidad de obrar cuando contrajera matrimonio. Esto conllevó el otorgar la plena capacidad a la mujer para comparecer en juicio por sí misma y litigar sobre los bienes parafernales ${ }^{59}$.

Estos cambios producidos en esta segunda etapa se dieron en muy poco tiempo, y fueron los causantes de dar un nuevo rumbo a España. Tras la muerte de Franco, nació Jornadas Nacionales por la Liberación de la Mujer organizadas por la

\footnotetext{
${ }^{56}$ Ley 7/1970, de 4 de julio, de modificación del capítulo V del título VII del libro I del Código Civil, sobre adopción.

${ }^{57}$ Ley 31/1972, de 22 de julio, sobre modificación de los artículos 320 y 321 del Código Civil y derogación del número 3 del artículo 1.880 y de los artículos 1.901 a 1.909 , inclusive, de la Ley de Enjuiciamiento Civil.

${ }_{58}$ Exposición de motivos de la Ley 31/1972, de 22 de julio.

${ }^{59}$ Ley 14/1975, de 2 de mayo, sobre reforma de determinados artículos del Código Civil y del Código de Comercio sobre la situación jurídica de la mujer casada y los derechos y deberes de los cónyuges.
} 
Plataforma de Organizaciones de Mujeres de Madrid, aunque durante la Transición democrática creció el movimiento feminista con nuevas agrupaciones de mujeres, y en este fervor nació la Constitución Española, reconociendo la igualdad entre las personas.

\section{Conclusiones}

Como se puede extraer del estudio que hemos realizado, la mujer ha sufrido un cambio importante de roles, avanzando durante la II República y sufriendo un gran retroceso en la Dictadura, pero que no fue igual durante todo ese período. Creemos así que gracias a ese proceso evolutivo la mujer hoy puede gozar de los derechos que le asisten, y los tres momentos fueron igual de importantes para culminar el presente.

Antes de la II República, la mujer tenía un proyecto de vida muy simple; casarse y fundar una familia, bajo la "protección" del marido. Pero con la llegada de la República la situación cambia, los partidos de izquierdas amenizan a las mujeres para que salgan a luchar en defensa de sus derechos y libertades, sin embargo, tal como hemos podido dejar constancia en este artículo, ellos mismos eran reacios a reconocerlas sus facultades. Esto nos lleva a afirmar que los propios partidos republicanos de forma implícita y tal como demostraron en distintos momentos pensaban que la mujer era un ser endeble. Sin embargo, el papel fundamental en este momento lo tuvieron las mujeres republicanas que defendían la igualdad de sexos, principalmente de Clara Campoamor. Es cierto que la República utilizó la imagen de la mujer para obtener más adeptos en sus filas, pero realmente dudaban de la capacidad de la mujer para tomar decisiones. No podemos decir que se tratara de una época en el que en las filas del gobierno estuvieran mujeres, había dos.

Tal como hemos dicho, "el plato fuerte" llegó con reconocer el voto a las mujeres, pero no se puede afirmar que fue gracias a los partidos de izquierdas, ni mucho menos, de hecho, hemos visto las alegaciones que llevaron a cabo en las cortes constituyentes los diputados de esa ideología. Por ello mismo, nos atrevemos a afirmar que, si la mujer durante la República pudo demostrar que podía ser más que mujer, madre y esposa, fue gracias a Clara Campoamor, sin desmerecer a Victoria Kent. Mujeres que, tras el estallido de la guerra civil, murieron o tuvieron que exiliarse.

Hemos visto como organizaciones como la Sección Femenina tuvieron especial importancia durante la guerra civil, luchando en la retaguardia, auxiliando a los soldados y dándoles los cuidados vitales. Tampoco se puede obviar la importancia que tuvo que mujeres republicanas llegaran a luchar "arma en mano" en el frente, por unas libertades de las que hoy podemos disfrutar. Desde un punto de vista neutral, hay que reconocer que la mujer, de un lado y de otro, ha tenido un papel transcendental en la historia española.

En el período de la Dictadura, hemos podido ver que los derechos y la capacidad de obrar de la mujer quedaron suprimidos. No podemos negar el elemento negativo que esto tiene, pero, sin justificar, podemos entender que en esa época las libertades se restringieran teniendo en cuenta la situación que precedió a la época, pero que fue la consecuencia directa de que la mujer luchara aún más por sus libertades y derechos que les habían sido restringidos.

En definitiva, creemos que la importancia de la mujer tanto de corte fascista y como de corte republicana fue vital en la historia de España para el reconocimiento de la 
igualdad en una sociedad que se caracteriza actualmente por ser social, democrática y de derecho. De esta forma, como señala Pérez Royo, "la Constitución pone fin a la situación de desigualdad jurídica que el matrimonio suponía para la mujer" 60 , aunque nos atrevemos a decir, la Constitución pone fin a la situación de desigualdad jurídica que la mujer había venido sufriendo, puesto que marca el comienzo de una nueva época, y el fin de la anterior.

\section{Bibliografía}

ESTARLICH MARTORRELL, M. (2018) La mujer en los años de la II República: una lectura propia, Revista hispanoamericana de historia de las ideas, núm. 39.

CAMPOAMOR, C. (2001) Mi pecado mortal. El voto femenino y yo, Instituto Andaluz de la Mujer, Sevilla

CASTÁN TOBEÑAS, J. (1955) La condición social y jurídica de la mujer. La diferenciación de los sexos en sus aspectos biológico, sociológico, ético y jurídico, Reus, Madrid.

GARCÍA BASAURI, M. (1978) La mujer en el reinado de Alfonso XIII. Una aproximación al primer movimiento feminista español, Tiempo de Historia, núm. 46

GIL GASCÓN, F. y GÓMEZ GARCÍA, S. (2014). El uso propagandístico de la mujer nacional durante la guerra civil: 'noticiario español' (1938-1939), Índex Comunicación, núm. 4.

GÓMEZ BLESA, M. (2010) Modernas y vanguardistas: mujer y democracia en la II República, Ediciones del Laberinto, Madrid.

MARTÍNEZ SIERRA, M. (1931) La mujer española ante la República, Ediciones de la Esfinge, Madrid.

MORANT, I. (2006) Historia de las mujeres en España y América latina, Cátedra, Madrid, p. 442. Véase también a PECHARROMÁN, J. L., (2006) Segunda República Española (1931-1936). Biblioteca Nueva, Madrid.

MORAGA GARCÍA, M. (2008) Notas sobre la situación jurídica de la mujer en el franquismo, Feminismos

NASH, M. (2003) Dones ciutadanes a Catalunya: la Segona República, Historia de les dones, Setmanari el temps, Valencia, núm. 4.

NICOLÁS MARÍN, E. (2005) La libertad encadenada. España en la dictadura franquista 1939-1975, Madrid, Alianza.

NUÑEZ PEREZ, G., (1993) Evolución de la situación laboral de las mujeres en España durante la Segunda República (1931-1936). Cuadernos Relaciones laborales, núm. 3.

ORTIZ HERAS, M. (2006) Mujer y Dictadura Franquista, Aposta. Revista de ciencias Sociales, núm. 28.

OLIVER OLMO, P. y CUBERO IZQUIERDO, M. C., (2020) De los controles disciplinarios a los controles securitarios, Ediciones Universidad de Castilla la Mancha.

${ }^{60}$ PÉREZ ROYO, J. (1996) Curso de Derecho Constitucional, Marcial Pons, Madrid, p. 322. 
PAJOT, G. (1954) La mujer casada en el derecho comparado, Revista de derecho notarial, Madrid.

PESTAÑA RUIZ, C. (2015) Evolución jurídica de la mujer casada en el sistema matrimonial español de la época preconstitucional, Revista de Estudios Jurídicos, Jaén, núm. 15

PÉREZ ROYO, J. (1996) Curso de Derecho Constitucional, Marcial Pons, Madrid.

RAMOS PALOMO, M. (2001) Feminismo y acción colectiva en la España de la primera mitad del siglo XX, en Manuel Ortiz Heras, David Ruiz González e Isidro Sánchez Sánchez (Coordinadores), Movimientos sociales y estado en la España contemporánea, Cuenca, UCLM.

VENTURA FRANCH, A. (1999) Las Mujeres y la Constitución Española de 1978, Ministerio de Trabajo y Asuntos Sociales, Instituto de la Mujer, Madrid.

ZAMBRANO, M. (1998) Delirio y Destino (los veinte años de una española). Barcelona, Mondadori España. 